\title{
Malignant Great Vessel Neoplasm
}

National Cancer Institute

\section{Source}

National Cancer Institute. Malignant Great Vessel Neoplasm. NCI Thesaurus. Code C4575.

A malignant neoplasm arising from the great vessels. 